\title{
A Contrastive Study of Image Repair Strategies Between Chinese and English Corporate Apologies
}

\author{
Zhanghong $\mathrm{Xu}^{1}$ (Corresponding author), \& Shuyu $\mathrm{Lin}^{2}$ \\ School of English for International Business, Guangdong University of Foreign Studies, Guangzhou, China \\ ${ }^{1}$ E-mail: $1458975262 @ q q . c o m$ \\ 2E-mail: 1224027819@qq.com
}

Received: April 10, 2020 Accepted: April 23, 2020 Online Published: April 28, 2020

doi:10.11114/ijecs.v3i1.4817

URL: https://doi.org/10.11114/ijecs.v3i1.4817

\begin{abstract}
In the era of globalization, social media have become important communication tools for enterprises in crisis. Corporate apologies are issued via social media to repair the tarnished corporate image, which might affect their survival. However, the way of apologizing varies from language/culture to language/culture. This study aims to investigate how Chinese and English corporate apologies are linguistically presented and to explore how damaged corporate image in different culture is repaired respectively. Under the framework of Benoit's image repair strategies and CCSARP, and based on quantitative and qualitative analysis of the collected data, this paper makes a contrastive study of Chinese and English corporate apologies. The results show that Chinese and English corporate apologies share great similarities in using the strategies of mortification and corrective actions, while they are different in terms of other specific tactics such as bolstering, good intentions, defeasibility and minimization. It is also found that the denial is the least used strategy by both Chinese and English corporations to repair their tarnished image. Furthermore, they are quite $t$ similar in using IFIDs, while intensifiers and hedges are more frequently employed in Chinese corporate apologies.
\end{abstract}

Keywords: Chinese and English Corporate apologies, apologies in catering industry, image repair strategies, contrastive study

\section{Introduction}

The past few decades have seen a number of high-profile crises that have precipitated various corporations into a vulnerable situation, among which are McDonald's sale of overdue food, KFC's chicken crisis, Haidilao's hygienic problem and Grandma's hygienic scandal. Given the changing media environment and the explosive growth of social media, the choice of communication platform is a critical factor to successful crisis communication (Ki \& Nekmat, 2014). If the corporations involved cannot respond to the crisis appropriately, their corporate image will be damaged and sometimes the corporation might even go bankrupt. In this case, an effective corporate apology plays an important role in successful crisis communication. As an apology is generally regarded as an organization's acceptance of responsibility for a crisis and asking for forgiveness (Benoit \& Drew, 1997; Coombs \& Hollady, 2008), corporate apology assists companies in regaining trust and reputation from their customers and in repairing their tarnished image. In recent years, corporations have turned increasingly to apologies as part of their crisis responses to repair their image. Maintaining a positive corporate image is essential for every enterprise, especially for the enterprises in catering industry, for any scandal an enterprise gets involved in will directly affect its public impression and sometimes destroy the enterprise.

Despite a large number of studies on corporate apologies in various industries, including mobile phones, laptops, electronics, airlines, dairy products, pharmaceutical industry ( Suman \& Surin, 2012; Page,2013; Lee \& Atkinson, 2019; Samuel \& Eric,2019), few studies (Lin, Deepa \& Ai, 2017; Zhang, 2018) have been made on corporate apologies in catering industry, which exerts a direct impact on customers' life and death, let alone make a contrastive study between different cultures/languages. Therefore, this paper will make a contrastive study of Chinese and English corporate apologies in catering industry, with an aim to find out the differences or similarities between Chinese and English corporate apologies by exploring the most salient linguistic features displayed in them as well as how to develop an effective corporate apology in catering industry.

This study aims to address the following two questions: (1) What strategies are used to repair image in Chinese and 
English corporate apologies in catering industry respectively? (2) What are the most salient linguistic features displayed in Chinese and English corporate apologies?

\section{Literature Review}

This section will review the related studies on image repair strategies and the current studies on corporate apologies, and then make a critical evaluation of the previous research, pointing out the strengths and weaknesses in the related studies.

\subsection{Image Repair Strategies}

Ulmer, Sellnow and Seeger (2007) observe that some public relations practitioners recommend that leaders use a carefully planned strategy to shift the blame, reduce responsibility and avoid damage to the company's reputation in response to a crisis, and such efforts are often termed as image repair strategies. In the past few decades, the research on crisis communication has witnessed a booming development, which motivated the development of image repair theories. Scholars like Benoit (1995), Coombs \& Hollady (1996), Burke (1970), Ware \& Linkugel (1973) and Scott \& Lyman (1968) have conducted a considerable amount of research on it. For example, Burke (1970) discussed two strategies for reducing guilt: victimage and mortification. Ware \& Linkugel (1973) offered four strategies for image repair: denial, bolstering, differentiation and transcendence. Benoit (1995) put forward five primary image repair strategies: denial, evasion of responsibility, reducing offensiveness, corrective action and mortification. Coombs \& Hollady's (1996) Situational Crisis Communication Theory (SCCT) identified five crisis response strategies: denial, distance, ingratiation, mortification and suffering of the accused. Among all the previous research, the image repair strategies of Benoit (1997) and the Situational Crisis Communication Theory (SCCT) of Coombs \& Hollady (1996) offer many insights into and feasible approaches to image repair by organizations, which have proven to significantly contribute to corporate image repair.

Previous studies also investigated the image repair strategies enacted by politicians (Benoit, 2006; Fisher Liu, 2007; Benoit, 2014), corporations (Benoit,1995; King, 2006; Harlow, Brantley \&Martin Harlow,2011) and celebrities (Benoit,1997; Brazeal,2008; Glantz, 2010). They claimed that the main communicative acts are the same for both corporations and individuals, and the differences reside in the fact that corporations may bring greater resources to image repair efforts than individuals (Benoit, 1997). For instance, Benoit (2014) evaluated President Obama's image repair effort and found that Obama relied heavily on mortification, corrective action and minimization to create new beliefs designed to improve attitudes towards him.

\subsection{Studies of Corporate Apologies}

In the past few decades, corporate apology has attracted considerable attention from various fields. Many scholars have made numerous studies on corporate apology from four perspectives, i.e. linguistic study, crisis communication and management, cross-cultural analysis and apology strategies.

In terms of linguistic study on corporate apologies, dozens of scholars have made numerous studies on corporate apology from different perspectives, such as pragmatics, genre analysis, interpersonal meaning, and rhetorical structures. The genre analysis of corporate apologies is the most widely made in China (He, 2012; Wang, 2015; Zheng, 2015; Dai, 2016; Fan, 2018). For example, Wang (2015) and Dai (2016) have studied the genre of corporate apology, which benefits practioners in acquiring the skills of $\mathrm{g}$ how to write an effective corporate apology. Apart from genre analysis, much attention has also been paid to the interpersonal meaning of apology. For instance, based on socio-functional study, Wang (2013) focused on the study of interpersonal meaning of apology. Zhao (2013) also studied the interpersonal meaning of person system and made a contrastive analysis of individual apology letters and company apology letters. Besides, some scholars also study corporate apologies from the perspective of pragmatics, such as Kampf (2009) who focused on more than 300 public apologies to study how apology letters are used to minimize the responsibility for wrongdoing. Harris et al (2006) explored in the field of pragmatics and demonstrated that apologies generated conflicts and controversy in the public domain.

Quite a number of studies have been done on crisis communication and management. Many scholars have focused on the effectiveness of corporate apologies (Greenberg \& Elliot, 2009; Page, 2013; Lee \& Atkinson, 2019; Samuel et al., 2019). For instance, Greenberg and Elliot (2009) made a case study on the effectiveness of Maple Leaf Food's apology and found that it is effective in regaining customer trust in company crisis. Samuel et al (2019) studied the role of corporate apology in forgiveness on future cooperation and found that apologies issued by entrepreneurs positively and significantly affect forgiveness and future cooperation. There are also scholars exploring the relationship between responsibility acceptance and sympathetic expression in corporate apologies (Page et al, 2010; Hargie et al, 2010; Lee \& Chung,2012). Lee \& Chung (2012) explored the effect of corporate apology on public anger relief, and the results show that active responsibility admittance relieved public anger more than passive responsibility admittance. 
What's more, much attention has paid to the intercultural study of corporate apologies. Some scholars have made a contrastive study of Chinese corporate apologies and those of other countries, especially Chinese and American corporate apologies (He, 2012; Wang, 2015; Li, 2017). He (2012) made a contrastive study of Chinese and American corporate apologies and found that though they have a lot of common characteristics, they are quite different in some aspects, such as frequency of use, specific selection of realization patterns and the influence of social distance. Based on the data of 16 apologies delivered by transnational corporations, $\mathrm{Li}$ (2017) examined intercultural corporate apologies within the framework of genre analysis, and the results demonstrated that intercultural corporate apologies are made not only for reputation and trust repair, but also illocutionary negotiation and discursive struggle.

Apart from that, other scholars also took interests in the study of apology strategies (Bergman and Kasper, 1993; Jiang \& Li, 2010; Chen, 2015; Xu \& Han, 2018). For example, Chen (2015) carried out a pragmatic study of Chinese corporate apologies posted on Weibo and her analysis showed the corrective relationships between apology strategies and the Cooperative Principle, as well as the characteristics of conversational implicatures generated by flouting some certain maxims. Zhou (2001) studied how apology strategies related itself to politeness principle and found that politeness principle plays an indispensable role in business activities. Bergman and Kasper (1993) conducted a research on the strategies in native and nonnative apology and found that contextual factors operated differentially in the strategy selection.

From the above literature review, we can find that the studies on corporate apologies are mainly related to the fields of linguistics and communication, in which the effectiveness of corporate apologies and crisis communication have attracted most people's attention. Linguistic studies on corporate apologies are mainly focused on genre analysis, interpersonal meaning and pragmatic analysis. Apart from these two fields, scholars in China pay attention to the cross-cultural studies on it, especially the studies between China and America. The study of apology strategies has also caught much attention among scholars. Though the effectiveness of corporate apologies has been investigated, little is known about the corporate apologies in catering industry, and scant attention has been paid to contrastive studies of image repair strategies in corporate apologies between different cultures/languages. Thus, to bridge the gap, corporate apology in catering industry should be studied in greater depth.

\section{Theoretical Framework and Research Methodology}

\subsection{Theoretical Framework}

\subsubsection{Benoit's Image Repair Strategies}

According to Benoit (1997), image is essential to organizations as well as individuals in the field of public relations, especially in the case of crises or scandals. Previous studies (Bradford \& Garret,1995; Coombs, 2007) have demonstrated that apologies had several positive effects in a corporation's handling of a crisis. So it is necessary to study how corporations employ image repair strategies to make apologies in crises or scandals. Since Benoit's image repair strategies have greatly influenced the process of image repair across the world, this paper is going to apply this framework to analyze Chinese and English corporate apologies so as to find out the differences and similarities between them. According to the framework of Benoit (1995), the image repair strategies can be categorized as shown in Table 1:

Table 1. Benoit's Image Repair Strategies

\begin{tabular}{|c|c|c|}
\hline General strategy & Tactic & Key Characteristic \\
\hline \multirow{3}{*}{ Denial } & Simple denial & To claim the offensive act in question did not occur \\
\cline { 2 - 3 } & Shift blame & $\begin{array}{r}\text { To deny personal responsibility for the act by indicting } \\
\text { someone else for the act in question }\end{array}$ \\
\hline \multirow{4}{*}{ Evade responsibility } & Provocation & $\begin{array}{c}\text { The act was committed, but it was in response to another } \\
\text { wrong act }\end{array}$ \\
\cline { 2 - 3 } & Defeasibility & $\begin{array}{c}\text { The act was committed, but the accused could not help it; } \\
\text { it was beyond one's control }\end{array}$ \\
\cline { 2 - 3 } & Accident & The act was committed, but it was an accident \\
\cline { 2 - 3 } & Good intentions & $\begin{array}{c}\text { The act was committed, and it had negative consequences, } \\
\text { but the accused meant well }\end{array}$ \\
\hline & Bolstering & The accused did this offensive act, but the accused has \\
\hline
\end{tabular}




\begin{tabular}{|c|c|c|}
\hline \multirow{6}{*}{ Reduce offensiveness } & & $\begin{array}{l}\text { also done a number of positive things, or has a number of } \\
\text { positive attributes }\end{array}$ \\
\hline & Minimization & The act was not as bad as critics make it out to be \\
\hline & Differentiation & The act was not as bad as other bad acts \\
\hline & Transcendence & $\begin{array}{l}\text { The act can be excused in the context of higher } \\
\text { considerations }\end{array}$ \\
\hline & Attack accuser & $\begin{array}{l}\text { The act is being characterized by someone who cannot be } \\
\text { trusted, etc. }\end{array}$ \\
\hline & Compensation & The accused tries to reimburse those hurt by the act \\
\hline Corrective action & & $\begin{array}{l}\text { The accused promises to fix the problem, restore the } \\
\text { situation, or in some way amend the consequences of the } \\
\text { offense }\end{array}$ \\
\hline Mortification & & Expressing regret, ask for forgiveness \\
\hline
\end{tabular}

\subsubsection{CCSARP}

Blum-Kulka and Olshtain (1989) claimed that by apologizing, the speaker committed a violation of social norms and admitted that s/he is at least partially involved in its cause. According to the Cross-Cultural Speech Act Realization Pattern (CCSARP), the linguistic realization of the act of apologizing can take the following strategies:

1) Illocutionary Force Indicating Device (IFID)

2) An explanation or account of the cause which brought about the offense

3) An expression of the speaker's responsibility for the offense

4) An offer of repair

5) A promise of forbearance

\subsection{Research Methodology}

\subsubsection{Data Collection}

The data used for analysis consists of a small-size corpus of 15 Chinese corporate apologies and 15 English corporate apologies issued during corporate crises that took place from 2008 to 2019. The companies selected are mostly well-known international companies in catering industry, such as McDonald's, KFC, Haidilao, and the Grandma's. Most of the corporate apologies are selected from the official websites of companies because they are original. However, not so many apology statements can be found from their official websites since some companies chose to post the apologies only for a short period of time. So other ways should be taken to collect more corporate apologies, such as Baidu, Weibo, Twitter, Facebook and other media. In this study, both spoken and written apologies are collected into the corpus, and several corporate apologies are selected from the apology videos posted by the CEOs or spokespersons of the companies.

In order to ensure that the findings are significant and enlightening, the corporate apologies selected are from the same industry--catering industry, which guarantees the comparability of Chinese and English corporate apologies. As these corporate apologies issued during corporate crisis have attracted most people's attention and the crises or incidents have been fiercely discussed, they can be taken as the most representative examples. Moreover, all the 30 corporate apologies are written or spoken by native speakers to ensure the authentic usage of language so as to find out the most salient linguistic features displayed in Chinese and English corporate apologies.

\subsubsection{Data Analysis}

A contrastive analysis will be made of the corporate apologies collected under the framework of Benoit's image repair strategies and CCSARP. As each corporate apology is issued under specific circumstances, it's necessary to regard every crisis as a case to study its whole process so as to have a comprehensive understanding of each apology.

After a careful reading of each apology, we can find out the image repair strategies used in the small-size corpus, and by using CCSARP, we can identify the linguistic strategies employed to perform the act of apology. In this study, quantitative analysis and qualitative analysis will be used to analyze the corporate apologies. Quantitative analysis is 
often associated with numerical analysis where data is collected, classified and then computed for certain findings, so it is employed to figure out the distribution of each strategy in both Chinese and English corporate apologies. Qualitative analysis is concerned with the analysis of data which can facilitate a deeper understanding of "why" a certain phenomenon occurs, thus it is used to give a detailed description of the strategies identified in each corporate apology. Because this study is related to two languages, some cultural differences will be addressed. After collecting the data of corporate apologies, we will analyze the data by using the linguistic software AntConc 2019, a freeware used by researchers in corpus linguistics, translation, and foreign language teaching. Harris et al. (2006) provide compelling evidence that the lemmas such as sorry and apologize are a crucial component in the general public's judgement of what counts as an apology. Therefore, by using the function of word list of software AntConc 2019, the use frequency of certain words like performative words (such as "apologize", "regret", "apology/apologies"), intensifiers and hedges like "incident" and "will" used in corporate apologies will be calculated. Thus we can make a comparison of their use frequencies between these two languages. The detailed descriptions of each strategy in corporate apologies will be given to find out the similarities and differences between them.

\section{Image Repair Strategies Employed in Chinese and English Corporate Apologies}

This section will first identify the types of strategy for image repair, and then present a detailed analysis of the major types of strategy employed in Chinese and English corporate apologies.

\subsection{Types of Strategy for Image Repair}

According to Benoit (1995), corporate apology belongs to one type of image repair discourse that can help repair the damaged corporate image in crises or scandals. To repair damaged corporate image, multiple strategies can be used in those corporate apologies. In this section, the image repair strategies used in Chinese and English corporate apologies will be discussed in detail.

Based on the data collected, the distribution of image repair strategies in Chinese and English corporate apologies is presented, as shown in Table 2. The result shows that the strategies of mortification and corrective action are the most frequently used strategies by both Chinese and English corporations, while the use frequencies of other tactics, such as good intentions, bolstering, defeasibility, differentiation and minimization are quite different and much less among these 30 corporate apologies.

Table 2. The Distribution of Image Repair Strategies in Chinese and English Corporate Apologies

\begin{tabular}{|c|c|c|c|}
\hline Image Repair Strategies & CCA $(\mathrm{n}=15)$ & $\mathrm{ECA}(\mathrm{n}=15)$ & In Total \\
\hline Mortification & 15 & 15 & 30 \\
\hline Corrective action & 15 & 15 & 30 \\
\hline Good Intentions & 0 & 2 & 13 \\
\hline Bolstering & 9 & 4 & 5 \\
\hline Differentiation & 3 & 2 & 1 \\
\hline Defeasibility & 1 & 0 & 5 \\
\hline Minimization & 3 & 2 & 1 \\
\hline Denial & 1 & 0 & \\
\hline
\end{tabular}

Notes: CCA: Chinese corporate apology, ECA: English corporate apology

As shown in Table 2, the strategies of mortification and corrective action enjoy the greatest popularity, which have been used in the 30 corporate apologies to shape responsible and positive corporate image. The corporations all choose to apologize to those who suffer from crises and promise to solve the problems and restore the situations. The use of these two strategies is regarded as the basic formula of apologies, which contributes to the restoration of the damaged corporate image. Apart from these two basic strategies, other tactics used in corporate apologies to repair their tarnished images include bolstering, differentiation and minimization. But these tactics are optional choices for the corporations, for they do not occur dominantly in all the apologies, and not all corporations choose to use these tactics. The strategies of denial, defeasibility and good intentions are seldom used in both Chinese and English corporate apologies.

\subsection{Analysis of Image Repair Strategies}

The employments of these image repair strategies will be analyzed in detail.

\subsubsection{Mortification}

Mortification refers to admitting guilt and seeking forgiveness. Past research on crisis communication stressed the 
importance of mortification in the aftermath of a crisis for which a company bears responsibility (Coombs, 2014). As shown in Table 2, the foremost strategy used in these 30 corporate apologies is mortification, which enables the companies to show their attitudes toward taking responsibility for the crises and to show their sincerity of apology and sympathy to the public, especially the consumers. Mortification does not show significant difference in frequencies between Chinese and English corporate apologies. Both Chinese and English corporate apologies tend to use this strategy to repair their tarnished images. It is found in the corpus that some companies usually choose to use mortification at the beginning of their apologies, so as to deepen their impression on the public. Some companies also use this strategy both at the beginning and at the end of their apologies. The following examples will show the uses of mortification in corporate apologies.

(1) We are sorry. A chicken restaurant without any chicken. It's not ideal. Huge apologies to our customers, especially those who travelled out of their way to find we were closed. (cf. KFC's apology statement)

(2) The campaign was meant to celebrate Halloween and the brand never intended to make any connection to historical events or to insult anyone in any way. We sincerely regret any offense this activation may have caused. (cf. McDonald's apology statement)

（3）无论如何, 对于此类事件的发生, 我们土分愧疚, 再次向各位顾客朋友表示诚挚的歉意。(Anyway, we are very sorry for the occurrence of this kind of incident. We would like to express our sincere apologies to our customers.)(cf. Haidilao's apology statement)

(4) 对于暴露出来的卫生问题, 我们深感抱慊和惭愧。(We are deeply sorry and ashamed of the hygienic problems that have been exposed.)(cf.Xibei's apology statement)

Take KFC as an example, when KFC ran out of its most important ingredient-chicken and had to temporarily shut down its 900 restaurants in the UK, angry customers took to social media. KFC took a risk by adding humor to its apology in a masterful and self-deprecating way. It took out a full-page ad in London newspapers that simply showed its signature chicken bucket with a reworked logo: "FCK". Paired with a brief explanation of the problem and a vow that wouldn't happen again, KFC saved its brand and its chicken. By using "We're sorry" as the title of its apology statement, KFC uses mortification at the beginning to show its attitude toward taking responsibility for the crisis as well as its sincerity of apology to the public.

\subsubsection{Corrective Action}

According to Benoit (1995), corrective action means that the accused promises to fix the problem, restore the situation, or in some way amend the consequences of the offense. It's obviously shown in Table 2 that, corrective action is also employed by all the 30 selected companies to rebuild their reputation by constructing their agentive role in providing remedies for the situations or crises. Both Chinese and English corporate apologies share large similarities in employing this strategy. Corporations are presented as the source of solutions rather than the cause of the problem. There is no doubt that the public want to know who should be responsible for the crises, and they care more about whether the problems have been resolved and whether some measures have been taken to address the problems. It is generally acknowledged that actions speak louder than words. It doesn't work by only expressing sympathy or mortification in apologies, and corrective actions should be taken to repair corporate images as well. Therefore, it is essential for corporations to state their corrective actions in their corporate apologies. The following examples will show the use of corrective action in corporate apologies.

(1) We have freshly baked our bread throughout the day in our more than 38,000 restaurants in 100 countries worldwide, and we have redoubled our efforts to ensure consistency and correct length in every sandwich we serve.(cf. Subway's apology statement)

(2) When listeria was discovered in the product, we launched immediate recalls to get it off the shelf, and then we shut the plant down. (cf. Maple Leaf Foods's apology statement)

(3) We're in the process of bringing in outside experts to help audit our company's culture and diversity and inclusion practice. This will allow us to identify our strengths and weaknesses. We will then set clear goals to do better. (cf. Papa John's apology statement)

(4) 目前, 我司已组成专项调查小组进驻门店, 调查事情原因。我们将及时公布调查结果。同时我们要求旗 下所有门店彻底自查, 规范操作, 落实制度, 引以为戒, 并派出督查小组随时跟进门店自查自纠结果。(At present, our company has set up a special investigation team to enter the stores to investigate the cause. We will release the findings in time. At the same time, we require that all our stores do thorough self-inspection, standardize operation, put the system into practice and take a warning, and send a supervision team to follow up the results of self-inspection and self-correction of stores at any time.) (cf. The Grandma's apology letter) 
(5) 我们愿意承担相应的经济责任和法律责任，但我们也有信心尽快杜绝这些问题的发生。我们也已布置在 海底捞所有门店进行整改, 并会后续公开发出整改方案, 也希望所有媒体和支持海底捞的顾客监督我们的工作。 (We are willing to assume corresponding economic and legal responsibilities, but we also have the confidence to put an end to these problems as soon as possible. We have also arranged all the chain stores in Haidilao for rectification, and will issue the rectification plan in public in the future. We also hope that all the media and customers supporting Haidilao will supervise our work.) (cf. Haidilao's apology letter)

From the above examples, we can see that both Chinese and English corporate apologies tend to use the strategy of corrective action. The companies in crises attach more importance on what they have done now and what they are going to do in the future to prevent such things from reoccurring. What's more, taking corrective actions enables the companies to render the public substantial and concrete steps to believe they will do better next time to prevent and address similar crises. Take Haidilao as an example, when the hygienic problem with Haidilao's was exposed, Haidilao immediately released an apology statement to apologize to the public. Apart from expressing their regret to the public, they took corrective actions to solve the problem, which left a positive impression on the public. By taking the responsibility and taking immediately corrective actions, Haidilao dispelled consumers' concerns and doubts so that it can regain the trust from its customers and repair its damaged image. Hence, the employment of the strategy of corrective actions does contribute to repairing damaged corporate image.

\subsubsection{Reducing Offensiveness}

The strategy of reducing offensiveness is realized by six tactics, i.e bolstering, minimization, differentiation, transcendence, attacking the accuser and compensation. These tactics are optional choices for companies, for they do not occur dominantly in all the apologies. Though both Chinese and English corporate apologies tend to use several tactics when apologizing, their frequencies of using these tactics are quite different. As shown in Table 2, it is found in the corpus that among these six specific tactics, bolstering is the most employed tactics in corporate apologies. Bolstering refers to the accused did this offensive act, but the accused has also done a number of positive things, or has a number of positive attributes. The use of bolstering in corporate apologies draws the public's attention to the past achievements or mission statements of the companies, which will distract the public's focus from the crisis events to the positive image of the companies. Consider the following examples:

(1) Papa John's is a pizza company with 12,000 corporate and franchise team members around the world. These are the people in your communities from all walks of life who work hard to provide you with better service and better pizza. (cf. Papa John's apology)

(2) For 47 years, customer satisfaction has been our top priority. (Subway’s apology)

(3) 坚守食品安全底线, 这是我们不变的原则。(It is our unchangeable principle to stick to the bottom line of food safety.)(cf. The Grandma's apology letter)

(4) 作为一个负责任的餐饮企业, 金鼎轩一直以来致力于为广大顾客提供安心放心的就餐体验。(As a responsible catering enterprise, Jindingxuan has been committed to providing customers with comfortable dining experience.)(cf. Jindingxuan's apology statement)

As example (1) shows, the CEO of Papa John's describes the number of its team members to bolster a large scope of its business, which will leave a good impression on the public. We can also see from example (2) that at the beginning of Subway's apology, it stressed its proud mission and long history to the public in order that the public will be attracted by the good points and mission statements of the company. Thus it can distract people's attention and then reduce the offensiveness.

As the figures in Table 2 attest, 9 of the 15 Chinese corporate apologies choose to employ the tactic of bolstering, while only 4 of the 15 English corporate apologies choose to use this tactic. Chinese corporate apologies use a bit more than that of English, which means Chinese corporations tend to bolster themselves when apologizing to attract people's attention to their past achievements or good missions.

\subsubsection{Evading Responsibility}

The strategy of evading responsibility is also a general image repair strategy that incorporates four specific tactics: provocation, defeasibility, accident and good intentions. Among these four tactics, 2 companies chose to use the tactic of good intentions and only one company chose to use the tactic of defeasibility. The apology of HEYTEA demonstrates this point.

(1) “由于距离下单时间已过四个小时且是外送, 途中有很多不可控因素...圆融门店由于靠近湖边, 开业以 来飞虫一直很多, 尤其夏季更加增多。(There are a lot of uncontrollable factors on the way, because the order time has passed four ours and it is take-away. Due to close to the lake, there are many flying insects around Yuanrong store, 
especially more in summer.")(cf. HEYTEA 's apology statement)

When the HEYTEA was complained that a fly was found in the milk tea, the service of HEYTEA has been heatedly discussed. Two days later, it issued a statement. From the time it responded to the crisis event, we can see that it failed to respond in time, which left a negative impression on the public. Though it apologized to the customer and the public, it stated that there were some uncontrollable factors, including insects around its shop. However, the public didn't trust it and regarded it as an irresponsible one. The HEYTEA not only failed to regain the trust from its customers but also damaged its image again. This is an unsuccessful apology. It's obviously seen from it that the use of defeasibility is not a good choice for corporations to repair their damaged images.

On the contrary, the use of tactic of good intentions makes for repairing corporate images. The following examples will illustrate this point.

(2) The campaign was meant to celebrate Halloween and the brand never intended to make any connection to historical events or to insult anyone in any way. (cf.McDonald's apology statement)

(3) Pepsi was trying to project a global message of unity, peace and understanding. (cf. Pepsi's apology statement) From the above two examples, we can see that both McDonald's and Pepsi stressed their good intentions at the beginning of their apology statements. To some extent, the crisis events will be considered less offensive because the current incident is caused by good intentions of making improvements.

\subsubsection{Denial}

As shown in the Table 2, only one company employed the strategy of denial in these 30 corporate apologies. Because all the companies confronted by crises in the corpus are accused of certain wrongdoing, they are regarded to be responsible for the crises in the view of the public. If they deny any wrongdoing in their apologies, they will directly leave a negative impression on the public and it is difficult for them to repair their tarnished images. The case of Beijing Jindingxuan Catering Co.,Ltd. demonstrates this point.

“经调查, 视频的真实情况是服务人员将为客人预先准备的干净饮用水倒入热水桶再次加热, 而并非网上所强调 的是客人喝剩下的水。(After investigation, the truth of the video is that the service personnel poured the clean drinking water prepared in advance for the guest into the water boiler and heat it again, instead of the situation that spread online that the water was leftover water by the customers.")(cf Jindingxuan's apology statement)

It can be seen from these sentences that Jindingxuan denied its behavior which was spread online. When Jindingxuan was complained that one of its workers poured the guest's leftover drinking water into the water boiler, it suddenly gave rise to fierce discussion. Though the company apologized to the public, it denied the claim that this incident was a misunderstanding by stating that the water was clean water rather than leftover water by the customers. However, nobody trusts it. The public are inclined to perceive it as irresponsible for the incident. We can see from it that the use of denial doesn't contribute to repairing corporate image when companies are confronted with crises. Therefore, companies should be very cautious about using the strategy of denial in their apologies.

\section{Linguistic Strategies Employed in Chinese and English Apologies}

\subsection{IFIDs}

According to Spence-Oatey (2008), an apology is a post-event speech act, where the event in question is perceived as requiring a remedial response, such as the apology. The most direct realization of an apology is done via an explicit illocutionary force indicating device (IFID), which selects a formulaic expression of regret (a performative verb) such as: (be) sorry, apologize, regret, etc (Blum-Kulka et al, 1989). By using the function of word list of software AntConc 2019, Table 3 is generated.

Table 3. Frequency of IFIDs Used in Corporate Apologies

\begin{tabular}{|c|c|c|}
\hline IFID Forms & Chinese Corporate Apologies & English Corporate Apologies \\
\hline Sorry & 3 & 8 \\
\hline Apologize & 11 & 9 \\
\hline Apology/Apologies & 12 & 3 \\
\hline Regret & 1 & 25 \\
\hline In Total & 27 & 5 \\
\hline
\end{tabular}

(1) We sincerely regret any offense this activation may have caused.(cf. McDonald's apology statement)

(2) Huge apologies to our customers, especially those who travelled out of their way to find we were closed.(cf. 
KFC's apology statement)

(3) 对于我公司长沙绝味食品营销有限公司“双 11 ”销售广告文案内容造成的不良影响我们深表歉意。(We deeply apologize for the negative influence caused by the contents of "Double Eleven" sales advertisement of our company Changsha Juewei Food Marketing Co., Ltd.(cf. Juewei’s apology statement)

(4) 对此我司再一次郑重向广大消费者及中国农业大学致以诚恳的歉意。(We would like to extend our sincere apologies to the consumers and China Agricultural University once again.)

Just as the above examples and Table 3 show, IFIDs like "sorry”, “apologize”, “apologies/apology”, “regret”, “抱兼/ 兼意”, “惭愧愧疚” are used frequently to fulfill the function of signaling regret and these words are usually modified by such intensifiers as "truly", "sincerely", "deeply", "very" and some others to strengthen their sincerity of apologies. As the figures in Table 3 attest, the frequencies of IFIDs used in Chinese and English corporate apologies are quite similar, which means both Chinese and English corporate apologies share great similarities in using IFIDs.

\subsection{Intensifiers}

Intensifiers are those "degree adverbs" that help intensify the meaning of other words. One way of expressing heightened emotion in speech is by using intensifying adverbs and modifiers (Brown \& Levinson, 1987). By using the function of word list of software AntConc 2019, Table 4 is generated.

Table 4. Frequency of Intensifiers Used in Corporate Apologies

\begin{tabular}{|c|c|c|}
\hline Intensifiers & $\begin{array}{c}\text { Chinese Corporate } \\
\text { Apologies }\end{array}$ & $\begin{array}{c}\text { English Corporate } \\
\text { Apologies }\end{array}$ \\
\hline Sincerely & 8 & 5 \\
\hline Deeply & 8 & 2 \\
\hline Seriously & 4 & 3 \\
\hline Very & 10 & 15 \\
\hline In Total & 30 & 5 \\
\hline
\end{tabular}

(1) On behalf of Starbucks, I want to sincerely apologize to all for the experience that six of your officers had in our store on July 4. (cf. Starbucks's apology statement)

(2) The fact that anyone has become ill eating at Chipotle is completely unacceptable to me and I am deeply sorry.(cf. Chipotler's apology letter)

(3) 无论如何, 对于此次事件给顾客造成的不愉快用餐体验, 我们土分愧疚, 在此向尊贵的吾红客人表示诚 挚的歉意。(In any case, we are very sorry for the unpleasant dining experience caused by this incident, and hereby express our sincere apologies to our honored guests.)(cf. Wuhong restaurant's apology letter)

(4) 近期, 全国部分餐厅可能出现产品断货的情况, 由此给消费者带来的不便, 我们深表兼意。(Recently, some restaurants in the country may have the situation that the product is out of stock, we deeply apologize for the inconvenience it brings to the consumers)(cf. McDonald's apology statement)

Apology intensification can be brought about by using the device of employing an intensifying expression within the IFID (Blum-Kulka et al, 1989). Just as the above examples and Table 4 show, intensifiers such as "sincerely", "deeply", "seriously","very" and some others are usually employed to modify IFIDs to convey sincerity of apologies. As the figures in Table 4 show, the frequencies of using intensifiers in Chinese corporate apologies are a bit more than that of English. It's a good choice for companies to express their apologies directly to their customers when they are in crisis, because it helps them to regain their customer's trust and contributes to repairing their damaged images.

\subsection{Hedges}

A hedge is a word or a phrase whose job is to make things fuzzier or less fuzzy. Hedges can be encoded in particles which may minimize one's shame at apologizing (Brown and Levinson, 1987) . Examples of hedges include "may", "possibly", "I think", "sort of", "will”, "some", "incident", "mistake" and some others. Hedges may be used to soften Face Threat Acts of suggesting or criticizing or complaining, by blurring the speaker's intent. By using the function of word list of software AntConc 2019, Table 5 is presented as follows . 
Table 5. Frequency of Hedges Used in Corporate Apologies

\begin{tabular}{|c|c|c|}
\hline Hedges & Chinese Corporate Apologies & English Corporate Apologies \\
\hline Incident & 23 & 6 \\
\hline Will & 19 & 2 \\
\hline $\begin{array}{c}\text { As...as } \\
\text { possible }\end{array}$ & 6 & 2 \\
\hline May & 2 & 20 \\
\hline In total & 50 & 10 \\
\hline
\end{tabular}

(1) Recently, we discovered a video of two Domino's team members who thought that their acts would be a funny YouTube hoax. We sincerely apologize for this incident. (cf.Domino's apology statement)

(2) We will take the necessary steps to ensure this doesn't happen again in the future.(cf.Starbucks' apology statement)

(3) 无论如何, 对于此类事件的发生, 我们十分愧疚, 再次向各位顾客朋友表示诚挚的歉意。(Anyway, we are very sorry for the occurrence of this kind of incident. We would like to express our sincere apologies to our customers.)(cf. Haidilao's apology letter)

(4) 我们将在确保食品原料完全符合国家法律法规和相关标注的前提下, 尽快恢复供应您所喜爱的产品。 (We will reinstate the supply of your favorite products as soon as possible, while ensuring that the food ingredients are in full compliance with national laws, regulations and relevant labeling.)(cf. McDonald's apology statement)

From Table 5, it's found that Chinese corporate apologies prefer adopting more hedges than that of English. Among them, the hedge “事件”(“incident” in English) is the most frequently used. Some companies apologize for the "incident", they are admitting that they have done something wrong, while, at the same breath, minimizing their responsibility. They refer only to the dismal event and not their offensive act by using the noun "incident", which blurs the act's negative and problematic meaning. It is also a way of minimizing responsibilities in apologies.

\subsection{Brief Discussion}

After a contrastive analysis of the employments of image repair strategies and linguistic strategies between Chinese and English corporate apologies, the results demonstrate that there are great similarities as well as differences between them. From the above analysis of these image repair strategies used in Chinese and English corporate apologies, we can see that the strategies of mortification and corrective actions combined with other tactics are used in corporate apologies to repair their images. Chinese and English corporate apologies share great similarities in using the strategies of mortification and corrective actions to repair their damaged images. However, there are also some differences between them. Their use frequencies of the tactics of good intentions, bolstering, defeasibility, differentiation and minimization are quite different due to specific purposes of the apologies. What's more, the denial is the least one used by corporations in both of them. As for the linguistic strategies employed in Chinese and English corporate apologies, it's found that both Chinese and English corporate apologies share large similarities in using IFIDs, while the uses of intensifiers and hedges are more saliently displayed in Chinese corporate apologies.

These differences can be explained by referring to Hall's cultural dimensions of high-context and low-context cultures (Hall,1976). People of low-context culture speak directly and say what they mean without unnecessary details, while people of high-context culture speak indirectly to show respect and maintain harmony. According to Hall (1976), China belongs to high-context culture, while western countries belongs low-context culture. Western people are more open and direct while Chinese people are more implicit and indirect, so when it comes to issuing an apology, western people choose to apologize more directly to protect the hearers' or customers' positive face. However, it's generally acknowledged that Chinese people are prone to "save face". When making an apology, they would like to use some implicit words to express their apologies and do as much as possible to keep their face. That's why the uses of bolstering, intensifiers and hedges are more saliently showed in Chinese corporate apologies.

\section{Conclusion}

After a contrastive analysis between Chinese and English corporate apologies, it is found thatthere are great similarities as well as differences between them in terms of strategies for image repair and pragma-linguistic strategies. As for the similarities, IFIDs and various intensifiers as well as hedges are frequently used to fulfill the function of speech act of apology, in which the uses of intensifiers and hedges are more saliently displayed in Chinese corporate apologies. In addition, both Chinese and English corporate apologies tend to employ the strategies of mortification and corrective actions to repair their damaged images and regain trust from the public, especially their customers. The combination of 
these two strategies constitutes the basic formula used to repair corporate images.

However, the sole employment of these two strategies is far from enough, and other specific tactics can be considered as optional based on specific crisis situations. Due to some cultural differences, the use frequencies of these tactics are quite different between these two languages, specifically, Chinese corporate apologies employ the tactic of bolstering more often than English corporate apologies do to draw the public's attention to the past achievements or mission statements of the companies. English corporate apologies tend to use the tactic of good intentions, while none of it can be found in Chinese corporate apologies. Besides, one Chinese company chooses to use the tactic of defeasibility to evade responsibility while none of it can be found in English corporate apologies. And the result shows that the defeasibility used in corporate apologies is not a good choice for repairing tarnished corporate image.

What's more, it is found that the use of denial in corporate apologies is the least used strategy by both of them to repair damaged image. Therefore, enterprises should be very cautious in using this strategy unless enough irrefutable evidence can be given to the public. When making an apology, enterprises should respond to the crisis event timely and utilize appropriate image repair strategies to repair their tarnished images.

\section{Acknowledgements}

The authors gratefully acknowledge the research grant (17SS03) delivered by Guandong University of Foreign Studies, and the support provided by the Research Centre for Business Culture and Philosophy of Culture, Guangdong University of Foreign Studies.

\section{References}

Bergman, M. L., \& G. Kasper. (1993). Perception and performance in native and nonnative apology. In G. Kasper \& S. Blum-Kulka. Interlanguage Pragmatics. New York: Oxford University Press, 82-87

Benoit, W. L. (1995). Accounts, excuses, and apologies. Albany NY: State University of New York Press.

Benoit, W. L. (1997). Image restoration discourse and crisis communication. Public Relations Review, 23, 177-186. https://doi.org/10.1016/S0363-8111(97)90023-0

Benoit, W. L., \& Drew, S. (1997). Appropriateness and effectiveness of image repair strategies. Communication Reports, 10(2), 153-163.

Benoit, W. L. (2006). Image repair in President Bush's April 2004 news conferences. Public Relations Review, 32, 137-143. https://doi.org/10.1016/j.pubrev.2006.02.025

Benoit, W. L. (2014). President Barack Obama's image repair on HealthCare.gov. Public Relations Review, 40, 733-738. https://doi.org/10.1016/j.pubrev.2014.7.003

Blum-Kulka, Shoshana, House, Juliane, Kasper, Gabriele, (1989). Cross Cultural Pragmatics: Requests and Apologies: A Cross-Cultural Study of Speech Act Realization Patterns (CCSARP). Ablex Publishing Corporation, Norwood, NJ.

Bradford, J. L., \& Garrett, D. E. (1995). The effectiveness of corporate communicative responses to accusations of unethical behaviour. Journal of Business Ethics, 14(11), 875-892.

Brazeal, L. M. (2008). The image repair strategies of Terrell Owens. Public Relations Review, 34, 145-150. https://doi.org/10.1016/j.pubrev.2008.03.021

Brown, P., \& Levinson, S. C. (1987). Politeness: Some Universals in Language Usage. New York: Cambridge University Press.

Burke, K. (1973). The Philosophy of Literary Form. Berkeley: University of California Press.

Chen, J. (2015). A pragmatic study of Chinese corporate apologies posted on Weibo. Guangdong University of Foreign Studies, China.

Coombs, W. T., \& Hollady, S. J. (1996). Communication and attributions in a crisis: An experimental study in crisis communication. Journal of Public Relations Research, 8, 279-295.

Coombs, W. T. (2007). Protecting organization reputations during a crisis: The development and situational crisis communication theory. Corporate Reputation Review, 10(3), 163-176.

Coombs, W. T., \& Hollady, S. J. (2008). Comparing apology to equivalent crisis response strategies: Clarifying apology's role and value in crisis communication. Public Relations Review, 34(3), 252-257. https://doi.org/10.1016/j.pubrev.2008.04.001

Dai, L. Y. (2016). Genre Features and Negotiation Strategies of Business Letters of Apology on Sina Weibo. Central 
China Normal University Journal of Postgraduates, 23(04), 87-93+115

Fisher Liu, B. (2007). President Bush's major post-Katrina speeches: enhancing image repair discourse theory applied to the public sector. Public Relations Review, 33, 40-48. https://doi.org/10.1016/j.pubrev.2006.11.003

Fan, Z. M. (2018). A contrastive study of genre analysis of Chinese and American corporate apologies. Shanxi University of Finance \& Economics, China.

Glantz, M. (2010). The Floyd Landis doping scandal: implications for image repair. Public Relations Review, 36, 157-163. https://doi.org/10.1016/j.pubrev.2009.09.002

Greenberg, J., \& Elliott, C. (2009). A cold cut crisis: Listeriosis, Maple Leaf Foods, and the politics of apology. Canadian Journal of Communication, 34, 189-204.

Hall, E. T. (1976). Beyond culture. Garden City, New York: Anchor.

Hargie, O., Stapleton, K., \& Tourish, D. (2010). Interpretations of CEO public apologies for the banking crisis: attributions of blame and avoidance of responsibility. Organization, 17(6),721-742.

Harlow, W. F., Brantley, B. C., \& Martin Harlow, R. (2011). BP initial image repair strategies after the Deepwater Horizon spill. Public Relations Review, 37, 80-83. https://doi.org/10.1016/j.pubrev.2010.11.005

Harris, Sandra, Grainger, Karen, Mullany, Louise, (2006). The pragmatics of political apologies. Discourse and Society, 17(6), 715-713.

He, Q. J. (2012). A cross-cultural analysis of American and Chinese corporate apologies. Fudan University, China.

Jiang, F., \& Li, F. (2010). Corporate apology strategy: based on stakeholder theory. Management studies of Sun Yat-Sen University, 5(04), 54-71

Kampf, Z. (2009). Public (non-) apologies: The discourse of minimizing responsibility. Journal of Pragmatics, 41, 2257-2270. https://doi.org/10.1016/j.pragma.2008.11.007

Ki, E. J., \& Nekmat, E. (2014). Situational crisis communication and interactivity: Usage and effectiveness of Facebook for crisis management by Fortune 500 companies. Computersin Human Behavior, 35, 140-147. https://doi.org/10.1016/j.chb.2014.02.039

King, G. III. (2006). Image restoration: an examination of the response strategies used by Brown and Williamson after allegation of wrongdoing. Public Relations Review, 32, 131-136. https://doi.org/10.1016/j.pubrev.2006.02.006

Li, Songqing. (2017). Apology as a crisis response strategy: a genre-based analysis of intercultural corporate apologies. International Journal of Linguistics and Communication, 5(1), 73-83.

Lin Zhu, Deepa Anagondahalli, Ai Zhang. (2017). Social media and culture in crisis communication: McDonald's and KFC crises management in China. Public Relations Review, 43, 487-492.

Scott, M. H., \& Lyman, S. M. (1968). Accounts. American Sociological Review, 33, 46-62.

Page, R. (2013). Saying "sorry": Corporate apologies posted on Twitter. Journal of Pragmatics, 62, 30-45. https://doi.org/10.1016/j.pragma.2013.12.003

So Young Lee, Lucy Atkinson. (2019). Never easy to say "sorry": Exploring the interplay of crisis involvement, brand image, and message appeal in developing effective corporate apologies. Public Relations Review, 45,178-188. https://doi.org/10.1016/j.pubrev.2018.12.007

Samuel L. Clarke, Eric S. Rhodes. (2019). Entrepreneurial apologies: The mediating role of forgiveness on future cooperation. Journal of Business Venturing Insights, 13. https://doi.org/10.1016/j.jbvi.2019.e00147

Spencer-Oatey, Helen. (2008). Face, impoliteness and rapport. In: Spencer-Oatey, H.(Ed), Culturally Speaking: Culture, Communication and Politeness Theory. London, 11-47.

Suman, L., \& Surin, C. (2012). Corporate apology and crisis communication: The effect of responsibility admittance and sympathetic expression on public's anger relief. Public Relations Review, 38, 932-934. https://doi.org/10.1016/j.pubrev.2012.08.006

Ulmer, R. R., Sellnow, T. L., \& Seeger, M. W. (2007). Effective crisis communication: Moving from crisis to opportunity. Thousand Oaks, CA: Sage.

Xu, C. H., \& Han, Y. Q. (2018). A study on apology strategies of Chinese enterprise: Based on company apology statements. Advertising Panorama, 4, 77-86.

Ware, B. L., \& Linkugel, W. A., (1973). The spoke in defense of themselves: On the generic criticism of apologia. 
Quarterly Journal of Speech, 59, 273-283.

Wang, M. (2013). Power and Solidarity in Apology: A Critical Discourse Analysis of Apologetic Announcement. Journal of Social Sciences, 32-35.

Wang, X. (2015). The Genre Study of English Corporate Apology Letter. Journal of Hubei University of science and technology, 35(07), 10-12

Zhang, Q. (2018). An analysis of enterprise response strategy based on image repair theory--case analysis of the "rat incident" of Haidilao. Journal of News Research, 9(10), 44-45+93.

Zhao, Y. (2013). An analysis of the use of person and the international meaning in apology letter. Journal of Chongqing Three Gorges University, 5(29), 121-124.

Zheng, C. H. (2015). A corpus-based genre analysis of corporate apologies. Guangdong University of Foreign Studies, China.

Zhou, R. Q. (2001). Pragmatic analysis of apology strategy in business activity. Foreign Language Education, 04, 91-94.

\section{Copyrights}

Copyright for this article is retained by the author(s), with first publication rights granted to the journal.

This is an open-access article distributed under the terms and conditions of the Creative Commons Attribution license (http://creativecommons.org/licenses/by/4.0/). 